\title{
Agama dengan Keikutsertaan Keluarga Berencana (KB) dan Pemilihan Jenis Alat Kontrasepsi pada Pasangan Usia Subur (PUS) di Desa Argomulyo Sedayu Bantul Yogyakarta
}

\author{
Eva Dyah Pratiwi ${ }^{1}$, Susiana Sariyati ${ }^{2}$ \\ 1,2Sekolah Tinggi IImu Kesehatan Alma Ata Yogyakarta \\ Jalan Ringroad Barat Daya No 1 Tamantirto, Kasihan, Bantul, Yogyakarta
}

\begin{abstract}
Abstrak
Keluarga Berencana dalam pandangan Agama masih sering timbul perbedaan-perbedaan pendapat, dimana ada yang memperbolehkan dan mengharamkan dengan jenis alat kontrasepsi yang dianjurkan di dalam program Keluarga Berencana. Hasil wawancara 30 responden yang dilakukan peneliti 10 diantaranya mengatakan agama memperbolehkan melakukan Keluarga Berencana, 15 diantaranya tidak memahami apakah agama tidak memperbolehkan atau memperbolehkan menggunakan Kontrasepsi, 5 diantaranya mengatakan agama tidak memperbolehkan menggunakan Kontrasepsi dikarenakan keyakinan mereka Keluarga Berencana dianggap menolak rezeki yang diberikan (anak). Tujuan penelitian ini untuk mengetahui hubungan antara Agama dengan keikutsertaan Keluarga Berencana dan Pemilihan Jenis Alat Kontrasepsi pada Pasangan Usia Subur (PUS) di Desa Argomulyo, Sedayu, Bantul, Yogyakarta Tahun 2014. Jenis Penelitian menggunakan penelitian observasional dengan rancangan desain cross sectional. Hasil penelitian responden yang mengikuti KB dalam agama Islam (67,2\%), Kristen (80\%) dan Khatolik (55,6\%). Responden yang Meyakini dan ikut KB (71,35\%) dan tidak meyakini dan ikut KB (66,5\%). Sebagian besar responden memilih kontrasepsi suntik dalam agama Islam $(28,4 \%)$ kristen (20\%), dan khatolik(44,4\%). Sedangkan meyakini memilih suntik (31,6\%) dan tidak meyakini juga sebagian besar memilih suntik (27,9\%). Kesimpulan tidak ada hubungan antara agama dengan keikutsertaan Keluarga Berencana. Tidak ada hubungan antara keyakinan dengan keikutsertaan Keluarga Berencana. Tidak ada hubungan antara agama dengan pemilihan jenis alat kontrasepsi. Ada hubungan antara keyakinan dengan pemilihan jenis alat kontrasepsi.
\end{abstract}

Kata Kunci: agama, jenis alat kontrasepsi, keyakinan, keikutsertaan KB

\section{Religion in Family Planning Participation and Contraceptives Selection of Reproductive Age Couples in Argomulyo Village, Sedayu, Bantul Yogyakarta}

\begin{abstract}
Family Planning (FP) in view of religion is still arise differences of opinion, where there are allow and forbid the recommended types of contraceptives in family planning programs. Based on the interviews with 30 respondents, 10 of them said that religion permits do family planning, 15 of them do not understand what religion does not permit or allow the use of contraceptives, 5 of them said that religion does not allow the use of contraceptives because of their belief in family planning was considered refusing sustenance given (children). The purpose of this study was to determine the relationship between religion in family planning participation and contraceptives selection of reproductive age couples in Argomulyo village, Sedayu, Bantul, Yogyakarta Year 2014. This study was observational with cross sectional design. The Results showed that there was $67.2 \%$ of Muslim participated FP, $80 \%$ of Christians and $55.6 \%$ of Catholics. $71.35 \%$ respondents were believing and participated FP and $66.5 \%$ respondents does not believe and participate FP. Most of respondents choose injection contraceptives, there was $28.4 \%$ in Islam, $20 \%$ of Christians, and $44.4 \%$ of Catholic. Respondents who believe in FP $31.6 \%$ choose injection contraceptive and $27.9 \%$ respondents who did not believe in FP also choose injection contraseptive. In conclusion, there was no relationship between religion and family planning participation, there was no correlation between faith and family planning participation, there was no relationship between religion and contraceptive selection, there was a relationship between faith and contraceptive selection.
\end{abstract}

Keywords: belief, contraceptives, FP participation, religion

Info Artikel:

Artikel dikirim pada 12 Januari 2015

Artikel diterima pada 12 Januari 2015 


\section{PENDAHULUAN}

Indonesia merupakan sebuah negara berkembang dengan jumlah peningkatan penduduk yang tinggi. Hasil sensus menurut publikasi Badan Pusat Statistik pada bulan Agustus 2010 antara lain jumlah penduduk Indonesia adalah 237.556.363 orang, terdiri atas 119.507.600 laki-laki dan 118.048.783 perempuan dengan laju pertumbuhan jumlah penduduk ini tentu saja akan berimplikasi secara signifikan terhadap kesejahteraan negara(1).

Program Keluarga Berencana merupakan salah satu cara menurunkan laju jumlah penduduk karena dari satu keluarga menurunkan manusia laki dan perempuan yang banyak, (menurut sensus global sekarang ini telah mencapai jumlah 7 milyar manusia) yang kemudian menimbulkan permasalahan kependudukan, jadi masalah kependudukan ini berawal dari keluarga(2). Berdasarkan Data dari BKKBN Jumlah pasangan usia subur (PUS) di Indonesia sekitar 43 juta orang. Saat ini akseptor KB di Indonesia 657.724 akseptor(2).

Data dari BKKBN di Provinsi DIY tahun 2012 Jumlah Pasangan Usia Subur adalah 545.950 orang, Peserta KB aktif 429.460 (78,66\%) dan Peserta KB baru 49.420 (9,05\%), sedangkan Pasangan Usia Subur di Kabupaten Bantul tahun 2013 sebanyak 141.463 orang, terdiri dari 125.018 (88,38\%) PUS aktif dan 16.382 (11,58\%) PUS baru. Jumlah pasangan usia subur di kecamatan Sedayu sebanyak 8.483 pasangan yang terdiri dari $7.761(91,49 \%)$ PUS aktif dan $722(8,51 \%)(2)$.

Hasil data komunitas yang dilakukan tahun 2014 di 6 dusun yaitu Kaliberot, Puluhan, Karang Lo, Pedes, Kemusuk kidul dan Surobayan merupakan dusun yang terletak di dusun Argomulyo, kecamatan Sedayu jumlah Pasangan Usia Subur yaitu Puluhan 129 PUS, Kaliberot 114 PUS, Pedes 235 PUS, Surobayan 230 PUS, Karang Lo 92 PUS, dan Kemusuk Kidul 97 PUS. Berdasarkan data komunitas 2014 jumlah akseptor KB di 6 dusun diatas didapatkan hasil yaitu Puluhan 47 PUS $(36,43 \%)$, Kaliberot 58 PUS (50,87\%), Pedes 128 PUS (52,10\%), Surobayan 143 PUS (63,91\%), Karang Lo 75 PUS (81,52\%), Kemusuk kidul 86 PUS (88,65\%).

Faktor-faktor yang mempengaruhi keikutsertaan Keluarga Berencana diantara lain pengetahuan, pendidikan, jumlah anak, dukungan keluarga, pendapatan, pekerjaan, dan agama(3). Untuk mendukung Program Keluarga Berencana tersebut, maka para pemuka agama Pusat telah membentuk forum antar umat beragama peduli keluarga sejahtera dan kependudukan (FAPSEDU) Pusat pada tanggal 17 Juni 2008. Dari urutan permasalahan dan peran yang akan dilakukan oleh FAPSEDU meliputi 3 hal yaitu masalah keluarga, masalah kependudukan, dan masalah keluarga berencana(2).

Masalah Keluarga Berencana yang masih sering timbul perbedaan-perbedaan pendapat, dimana ada yang memperbolehkan dan mengharamkan dengan jenis alat kontrasepsi yang dianjurkan di dalam program Keluarga Berencana(2).

Pandangan berbagai Agama tentang Keluarga Berencana yaitu yang pertama Agama Islam yang mengharamkan Jenis Kontrasepsi Vasektomi dan Tubektomi karena mempunyai sifat permanen tetapi ada juga agama islam yang membolehkan menggunakan kontrasepsi. Yang kedua agama khatolik yang diperbolehkan hanya KB alamiah atau Pantang Berkala saja sehingga untuk jenis alat kontrasepsi yang lain tidak diperbolehkan(2).

Berdasarkan pandangan setiap masingmasing agama yang berbeda-beda tersebut maka pelaksanaan Program Keluarga Berencana akan lebih sulit diterima terutama alat kontrasepsi yang ada diprogram Keluarga Berencana karena masingmasing agama mempunyai umat yang begitu mematuhi perintah agama yang dianutnya(2).

Dari hasil wawancara kepada 30 responden yang dilakukan pada saat studi pendahuluan, didapat 10 diantaranya mengatakan agama memperbolehkan melakukan Keluarga Berencana, 15 diantaranya tidak memahami apakah agama tidak memperbolehkan atau memperbolehkan menggunakan Kontrasepsi, 5 diantaranya mengatakan agama tidak memperbolehkan menggunakan Kontrasepsi dikarenakan keyakinan mereka Keluarga Berencana dianggap menolak rezeki yang diberikan (anak).

Tujuan penelitian ini untuk mengetahui hubungan antara Agama dengan keikutsertaan Keluarga Berencana dan Pemilihan Jenis Alat Kontrasepsi pada pasangan usia subur (PUS) di Desa Argomulyo, Sedayu, Bantul, Yogyakarta Tahun 2014.

\section{BAHAN DAN METODE}

Penelitian ini menggunakan metode penelitian observasional analitik yaitu suatu penelitian yang mencoba mengetahui mengapa masalah tersebut bisa terjadi, kemudian melakukan analisa hubungan antara faktor resiko (faktor yang mempengaruhi efek) dengan faktor efek (faktor yang dipengaruhi oleh resiko)(4). Pendekatan yang digunakan adalah dengan cross sectional. Populasi dalam penelitian ini adalah Semua pasangan usia subur (PUS) yang berada di Dusun Puluhan, Kaliberot, Karang Lo, Pedes, Surobayan, Kemusuk Kidul di Desa Argomulyo, Kecamatan Sedayu, Kabupaten Bantul yang berjumlah 916 PUS. 
Dalam penelitian ini, sampel penelitian diambil dengan menggunakan teknik total sampling atau sampling jenuh yaitu teknik penentuan sampel bila semua anggota populasi digunakan sebagai sampel(5).

Lokasi penelitian dilaksanakan yaitu di Desa Argomulyo, Kecamatan Sedayu, Kabupaten Bantul, Yogyakarta. Waktu penelitian dilaksanakan pada tanggal 3 Juni sampai 18 Juni Tahun 2014. Bahan dan alat yang digunakan adalah kuesioner. Jenis kuesioner yang digunakan berbentuk pilihan, dimana jawaban telah disediakan (closed ended item).

Variabel independen dalam penelitian ini adalah Agama pasangan usia subur (PUS) di Desa Argomulyo, Sedayu, Bantul, Yogyakarta. Variabel dependen dalam penelitian ini adalah keikutsertaan Keluarga Berencana dan pemilihan jenis alat kontrasepsi pada pasangan usia subur (PUS) di Desa Argomulyo, Sedayu, Bantul, Yogyakarta.

\section{HASIL DAN BAHASAN}

\section{Karakteristik Responden}

Tabel 1 menunjukkan sebagian besar Istri berusia 20-35 tahun sejumlah 476 orang $(52,5 \%)$ dan Suami berusia $>35$ tahun sejumlah 523 orang $(57,7 \%)$ sedangkan sebagian kecil istri berusia $<20$ tahun sejumlah 4 orang $(0,4 \%)$ dan suami berusia $<20$ tahun sejumlah 1 orang $(0,1 \%)$. Sebagian besar Istri berpendidikan SMA sejumlah 548 orang $(60,4 \%)$ dan sebagian kecil berpendidikan tidak tamat SD sejumlah 9 orang $(1,0 \%)$, sedangkan pendidikan suami sebagian besar SMA sejumlah 563 orang $(62,1 \%)$ dan sebagian kecil berpendidikan tidak tamat SD sejumlah 10 orang (1,1\%). Pasangan usia subur (PUS) sebagian besar memiliki anak <2 orang sejumlah $705(77,7 \%)$ dan sebagian kecil memiliki belum mempunyai anak sejumlah 44 orang $(4,9 \%)$.Sebagian besar pasangan usia subur (PUS) beragama Islam sejumlah 888 orang $(97,9 \%)$ dan sebagian kecil beragama Khatolik sejumlah 9 orang $(1,0 \%)$.

\section{Keyakinan Menurut Agama Pasangan Usia Subur (PUS)}

Tabel 2 menunjukan pada umumnya keikutsertaan Keluarga Berencana di desa Argomulyo tidak berdasarkan ada/tidak adanya keyakinan/ pemahaman keagamaan, tetapi berdasarkan pertimbangan lain yaitu kesehatan.

\section{Keikutsertaan Pasangan Usia Subur (PUS) dalam Keluarga Berencana.}

Tabel 3 menunjukan sebagian besar pasangan usia subur (PUS) mengikuti Keluarga Berencana
Tabel 1. Distribusi frekuensi Karakteristik Responden Pasangan Usia Subur (PUS) Berdasarkan Umur, Agama, Pendidikan, Pekerjaan di Desa Argomulyo, Sedayu, Bantul, Yogyakarta Tahun 2014

\begin{tabular}{|c|c|c|}
\hline Karakteristik & $f$ & $\%$ \\
\hline \multicolumn{3}{|l|}{ Umur Istri } \\
\hline$<20$ tahun & 4 & 0,4 \\
\hline 20- 35 tahun & 476 & 52,5 \\
\hline$>35$ tahun & 427 & 47,1 \\
\hline \multicolumn{3}{|l|}{ Umur Suami } \\
\hline$<20$ tahun & 1 & 0,1 \\
\hline 20- 35 tahun & 383 & 42,2 \\
\hline$>35$ tahun & 523 & 57,7 \\
\hline \multicolumn{3}{|l|}{ Pendidikan Istri } \\
\hline Tidak tamat SD & 9 & 1,0 \\
\hline SD/sederajat & 82 & 9,0 \\
\hline SMP/sederajat & 150 & 16,5 \\
\hline SMA/sederajat & 548 & 60,4 \\
\hline Diploma/lebih tinggi & 118 & 13,0 \\
\hline \multicolumn{3}{|l|}{ Pendidikan Suami } \\
\hline Tidak tamat SD & 10 & 1,1 \\
\hline SD/sederajat & 78 & 8,6 \\
\hline SMP/sederajat & 127 & 14,0 \\
\hline SMA/sederajat & 563 & 62,1 \\
\hline Diploma/lebih tinggi & 129 & 14,2 \\
\hline \multicolumn{3}{|l|}{ Jumlah Anak } \\
\hline Belum punya anak & 44 & 4,9 \\
\hline$<2$ orang & 705 & 77,7 \\
\hline$>2$ orang & 158 & 17,4 \\
\hline \multicolumn{3}{|l|}{ Agama Istri } \\
\hline Islam & 888 & 97,9 \\
\hline Kristen & 10 & 1,1 \\
\hline Budha & 0 & 0 \\
\hline Hindu & 0 & 0 \\
\hline Khatolik & 9 & 1,0 \\
\hline Khonghucu & 0 & 0 \\
\hline \multicolumn{3}{|l|}{ Agama Suami } \\
\hline Islam & 888 & 97,9 \\
\hline Kristen & 10 & 1,1 \\
\hline Budha & 0 & 0 \\
\hline Hindu & 0 & 0 \\
\hline Khatolik & 9 & 1,0 \\
\hline Khonghucu & 0 & 0 \\
\hline Jumlah & 907 & 100 \\
\hline
\end{tabular}

Sumber: Data Primer Tahun 2014

Tabel 2. Distribusi Keikutsertaan KB Berdasarkan Ada/Tidak Adanya Keyakinan/ Pemahaman Keagamaan pada Pasangan Usia Subur (PUS) di Desa Argomulyo, Sedayu, Bantul, Yogyakarta Tahun 2014

\begin{tabular}{lcc}
\hline \multicolumn{1}{c}{ Keyakinan } & $\mathbf{f}$ & $\boldsymbol{\%}$ \\
\hline Ya & 136 & 15,0 \\
Tidak & 771 & 85,0 \\
Jumlah & 907 & 100 \\
\hline
\end{tabular}

Sumber: Data Primer Tahun 2014 
sejumlah 610 orang $(67,3 \%)$ dan responden yang tidak mengikuti Kelurga Berencana sejumlah 297 orang $(32,7 \%)$.

Tabel 3. Keikutsertaan Keluarga Berencana pada Pasangan Usia Subur (PUS) di Desa Argomulyo, Sedayu, Bantul, Yogyakarta Tahun 2014

\begin{tabular}{lcl}
\hline Keikutsertaan KB & f & \% \\
\hline Ikut serta & 610 & 67,3 \\
Tidak Ikut Serta & 297 & 32,7 \\
Jumlah & 907 & 100 \\
\hline
\end{tabular}

Sumber: Data Primer Tahun 2014

\section{Jenis Kontrasepsi yang Digunakan Pasangan Usia Subur (PUS)}

Hasil penelitian terhadap pemilihan jenis kontrasepsi pada pasangan usia subur (PUS) yang ber-KB di Desa Argomulyo, Sedayu, Bantul, Yogyakarta tahun 2014 disajikan pada Tabel 4.

Tabel 4. Pemilihan Jenis Kontrasepsi pada Pasangan Usia Subur (PUS) yang ber- KB di Desa Argomulyo, Sedayu, Bantul, Yogyakarta Tahun 2014

\begin{tabular}{lcc}
\hline Jenis Lontrasepsi & $\mathbf{f}$ & $\mathbf{\%}$ \\
\hline Pil & 92 & 15,1 \\
IUD/Spiral & 113 & 18,5 \\
Suntik & 258 & 42,3 \\
Implant & 24 & 3,9 \\
Kondom & 57 & 9,3 \\
Sterilisasi & 25 & 4,1 \\
Pantang Berkala & 31 & 5,1 \\
Lain-Lain (MAL. Senggama Terputus) & 10 & 1,6 \\
Jumlah & 610 & 100,0 \\
\hline
\end{tabular}

Sumber: Data Primer Tahun 2014

Tabel 4 menunjukan sebagian besar pasangan usia subur (PUS) yang mengikuti KB memilih jenis kontrasepsi suntik sejumlah 258 orang $(42,3 \%)$, sedangkan yang memilih jenis kontrasepsi Metode Amenorea Laktasi (MAL) dan senggama terputus jumlahnya paling sedikit sejumlah 10 orang $(1,6 \%)$.

\section{Hubungan Agama Pasangan Usia Subur (PUS) dengan keikutsertaan KB}

Tabel 5 menunjukkan pasangan usia subur (PUS) beragama Islam yang mengikuti KB sejumlah 597 orang $(67,2 \%)$ dan tidak mengikuti KB sejumlah 291 orang $(32,8 \%)$. Responden beragama Kristen yang mengikuti KB sejumlah 8 orang $(80,0 \%)$ dan tidak mengikuti KB sejumlah 2 orang $(20,0 \%)$. Responden beragama Khatolik yang mengikuti KB sejumlah 5 orang $(55,56 \%)$ dan yang tidak mengikuti KB sejumlah 4 orang $(44,4 \%)$.
Tabel 5. Tabulasi Silang dan Uji Statistik Hubungan Agama dengan Keikutsertaan Keluarga Berencana (KB) di Desa Argomulyo, Sedayu, Bantul, Yogyakarta Tahun 2014

\begin{tabular}{|c|c|c|c|c|c|c|c|c|}
\hline \multirow{3}{*}{ Agama } & \multicolumn{4}{|c|}{ Keikutsertaan KB } & \multirow{2}{*}{\multicolumn{2}{|c|}{ Total }} & \multirow{3}{*}{$\chi_{\text {hitung }}^{2}$} & \multirow{3}{*}{ p-value } \\
\hline & \multicolumn{2}{|c|}{ Ya } & \multicolumn{2}{|c|}{ Tidak } & & & & \\
\hline & $f$ & $\%$ & f & $\%$ & $f$ & $\%$ & & \\
\hline Islam & 597 & 67,2 & 291 & 32,8 & 888 & 100 & \multirow{4}{*}{1,297} & \multirow{4}{*}{0,523} \\
\hline Kristen & 8 & 80,0 & 2 & 20,0 & 10 & 100 & & \\
\hline Khatolik & 5 & 55,6 & 4 & 44,4 & 9 & 100 & & \\
\hline Total & 610 & & 297 & & 907 & 100 & & \\
\hline
\end{tabular}

Sumber: Data Primer Tahun 2014

Hasil perhitungan statistik menggunakan uji chi-square seperti disajikan pada Tabel 5 diperoleh $p$-value sebesar $0,523>0,05$ sehingga dapat disimpulkan tidak ada hubungan antara agama dengan keikutsertaan Keluarga Berencana. Hal ini dikarenakan sebagian responden mengikuti KB karena kesehatan bukan karena agama mereka. Selain itu, beberapa agama memperbolehkan KB dengan alasan KB dianggap penting untuk menjaga kesehatan ibu dan anak, menunjang program pembangunan kependudukan lainnya dan menjadi bagian dari hak azasi manusia(2).

Dalam agama Islam perbedaan-perbedaan yang timbul atau yang masih ada, tidaklah mengenai gagasan atau gerakan KB itu sendiri, tetapi sekedar tentang cara-cara pendekatan dan alatalat kontrasepsi yang dipergunakan, yang untuk sebagian dianggap kurang atau tidak dibenarkan dan dipertanggungjawabkan(2).

\section{Hubungan Keyakinan Pasangan Usia Subur (PUS)} dengan Keikutsertaan KB

Tabel 6 menunjukkan pasangan usia subur (PUS) yang memiliki keyakinan dalam ajaran agama dengan keikutsertaan KB (agama melarang) yang mengikuti KB sejumlah 97 orang $(71,3 \%)$ dan yang tidak mengikuti KB sejumlah 39 orang $(28,7 \%)$. Responden yang memiliki tidak meyakini dalam ajaran agama dengan keikutsertaan KB (agama tidak melarang) yang mengikuti KB sejumlah 513

Tabel 6. Tabulasi Silang dan Uji Statistik Hubungan

Keyakinan dengan Keikutsertaan Keluarga

Berencana (KB) di Desa Argomulyo, Sedayu, Bantul, Yogyakarta

\begin{tabular}{|c|c|c|c|c|c|c|c|c|}
\hline \multirow{3}{*}{ Keyakinan } & \multicolumn{4}{|c|}{ Keikutsertaan KB } & \multirow{2}{*}{\multicolumn{2}{|c|}{ Total }} & \multirow{3}{*}{$\chi_{\text {hitung }}^{2}$} & \multirow{3}{*}{$p$-value } \\
\hline & \multicolumn{2}{|c|}{$\mathrm{Ya}$} & \multicolumn{2}{|c|}{ Tidak } & & & & \\
\hline & $f$ & $\%$ & $f$ & $\%$ & $f$ & $\%$ & & \\
\hline $\mathrm{Ya}$ & 97 & 71,3 & 39 & 28,7 & 136 & 100 & 203 & 0273 \\
\hline Tidak & 513 & 66,5 & 258 & 33,5 & 771 & 100 & $1, \angle 03$ & 0,213 \\
\hline Total & 610 & & 297 & & 907 & 100 & & \\
\hline
\end{tabular}

Sumber: Data Primer Tahun 2014 
orang $(66,5 \%)$ dan yang tidak mengikuti sejumlah 258 orang $(33,5 \%)$.

Hasil perhitungan statistik menggunakan uji chi-square seperti disajikan pada Tabel 6 diperoleh $p$-value sebesar $0,273>0,05$ sehingga dapat disimpulkan tidak ada hubungan antara keyakinan dengan keikutsertaan Keluarga Berencana.

Sehingga tidak ada pengaruh keyakinan terhadap keikutsertaan Keluarga Berencana disebabkan sebagian responden yang memiliki keyakinan bahwa ada hubungan antara agama dengan keikutsertaan KB tetapi mereka tetap ikut KB. Alasan mereka ikut KB yaitu mereka mengatakan agama melarang tetapi sebagian besar didalam agama ada kontrasepsi yang diperbolehkan sebagai contah agama Islam melarang sterilisasi tetapi suntik, IUD, pantang berkala dan lain-lain diperbolehkan(2).

\section{Hubungan Agama Pasangan Usia Subur dengan Pemilihan Jenis Alat Kontrasepsi}

Tabel 7 menunjukkan pasangan usia subur (PUS) beragama Islam sebagian besar memilih kontrasepsi suntik sejumlah 252 orang $(28,4 \%)$. Pasangan usia subur (PUS) beragama Kristen sebagian besar memilih suntik sejumlah 2 orang $(20 \%)$. Pasangan usia subur (PUS) beragama Khatolik sebagian besar memilih kontrasepsi suntik sejumlah 4 orang $(44,4 \%)$.

Hasil perhitungan statistik menggunakan uji chisquare seperti disajikan pada Tabel 7 diperoleh $p$-value sebesar $0,296>0,05$ sehingga dapat disimpulkan tidak ada hubungan antara agama dengan pemilihan jenis alat kontrasepsi.

Responden beragama Islam, Kristen, Khatolik sebagian besar memilih suntik dan KB Hormonal sebagai alat kontrasepsi yang digunakan. Hal ini disebabkan suntik dan KB hormonal tidak ada unsur pembunuhan karena unsur kerjanya mengentalkan lendir servik sehingga tidak bisa ditembus oleh sperma.

Menurut BKKBN agama Islam, Kristen, Budha, Hindu memperbolehkan menggunakan kontrasepsi suntik, pil, implant(2). Hal ini diperkuat oleh penelitian Loesy loeminto yang samasama menyebutkan bahwa tidak ada hubungan yang signifikan antara pengaruh agama dengan pemilihan kontrasepsi(6).

Islam mengatakan bahwa hukum KB bisa haram apabila bertujuan untuk membatasi kelahiran karena di Islam tidak ada pembatasan kelahiran, tapi hukum KB bisa menjadi mubah apabila dengan kehamilan dapat membahayakan.
Tabel 7. Tabulasi Silang Hubungan Agama dengan Pemilihan Jenis Alat Kontrasepsi di Desa Argomulyo, Sedayu, Bantul, Yogyakarta

\begin{tabular}{|c|c|c|c|c|c|}
\hline \multirow{2}{*}{$\begin{array}{l}\text { Pemilihan } \\
\text { Jenis KB }\end{array}$} & \multicolumn{3}{|c|}{ Agama } & \multirow{2}{*}{$\chi_{\text {hitung }}^{2}$} & \multirow{2}{*}{ p-value } \\
\hline & Islam & Kristen & Khatolik & & \\
\hline \multicolumn{6}{|c|}{ Tidak Memilih } \\
\hline f & 291 & 2 & 4 & 18,483 & 0,296 \\
\hline$\%$ & 32,8 & 20 & 44,4 & & \\
\hline \multicolumn{6}{|l|}{ PIL } \\
\hline$f$ & 91 & 1 & 0 & & \\
\hline$\%$ & 10,2 & 10 & 0 & & \\
\hline \multicolumn{6}{|l|}{ IUD } \\
\hline $\mathrm{f}$ & 111 & 2 & 0 & & \\
\hline$\%$ & 12,5 & 20 & 0 & & \\
\hline \multicolumn{6}{|l|}{ Suntik } \\
\hline f & 252 & 2 & 4 & & \\
\hline$\%$ & 28,4 & 20 & 44,4 & & \\
\hline \multicolumn{6}{|l|}{ Implant } \\
\hline f & 23 & 1 & 0 & & \\
\hline$\%$ & 2,6 & 10 & 0 & & \\
\hline \multicolumn{6}{|l|}{ Kondom } \\
\hline f & 57 & 0 & 0 & & \\
\hline$\%$ & 6,4 & 0 & 0 & & \\
\hline \multicolumn{6}{|l|}{ Sterilisasi } \\
\hline f & 25 & 0 & 0 & & \\
\hline$\%$ & 2,8 & 0 & 0 & & \\
\hline \multicolumn{6}{|c|}{ Pantang Berkala } \\
\hline $\mathrm{f}$ & 28 & 2 & 1 & & \\
\hline$\%$ & 3,2 & 20 & 11,1 & & \\
\hline \multicolumn{6}{|l|}{ Lain-Lain } \\
\hline f & 10 & 0 & 0 & & \\
\hline$\%$ & 1,1 & 0 & 0 & & \\
\hline \multicolumn{6}{|l|}{ Total } \\
\hline$f$ & 888 & 10 & 9 & & \\
\hline$\%$ & 100 & 100 & 100 & & \\
\hline
\end{tabular}

Sumber: Data Primer Tahun 2014

Tabel 8 menunjukkan pasangan usia subur (PUS) beragama Islam sebagian besar memilih kontrasepsi hormonal (Pil, Suntik, Implant) sejumlah 366 orang $(41,2 \%)$. Pasangan usia subur (PUS) beragama Kristen sebagian besar memilih kontrasepsi hormonal sejumlah 4 orang (40\%). Pasangan usia subur (PUS) beragama Khatolik sebagian besar memilih kontrasepsi hormonal sejumlah 4 orang $(44,4 \%)$.

Hasil perhitungan statistik menggunakan uji chisquare seperti disajikan pada Tabel 8 diperoleh $p$-value sebesar $0,397>0,05$ sehingga dapat disimpulkan tidak ada hubungan antara agama dengan pemilihan jenis alat kontrasepsi yang dikategorikan.

\section{Hubungan keyakinan Pasangan Usia Subur dengan Pemilihan Jenis Alat Kontrasepsi}

Tabel 9 menunjukkan pasangan usia subur (PUS) yang memiliki keyakinan bahwa ada 
Tabel 8. Tabulasi Silang Hubungan Agama dengan Pemilihan Jenis Alat Kontrasepsi yang dikategorikan di Desa Argomulyo, Sedayu, Bantul, Yogyakarta

\begin{tabular}{|c|c|c|c|c|c|}
\hline \multirow{2}{*}{$\begin{array}{c}\text { Pemilihan } \\
\text { Jenis KB }\end{array}$} & \multicolumn{3}{|c|}{ Agama } & \multirow{2}{*}{$\chi_{\text {hitung }}^{2}$} & \multirow{2}{*}{ p-value } \\
\hline & Islam & Kristen & Khatolik & & \\
\hline \multicolumn{6}{|c|}{ Tidak Memilih } \\
\hline f & 291 & 2 & 4 & 10,512 & 0,397 \\
\hline$\%$ & 32,8 & 20 & 44,4 & & \\
\hline \multicolumn{6}{|c|}{ KB Hormonal } \\
\hline f & 366 & 4 & 4 & & \\
\hline$\%$ & 41,2 & 40 & 44,4 & & \\
\hline \multicolumn{6}{|l|}{ IUD } \\
\hline f & 111 & 2 & 0 & & \\
\hline$\%$ & 12,5 & 20 & 0 & & \\
\hline \multicolumn{6}{|l|}{ Kondom } \\
\hline f & 57 & 0 & 0 & & \\
\hline$\%$ & 6,4 & 0 & 0 & & \\
\hline \multicolumn{6}{|l|}{ Sterilisasi } \\
\hline f & 25 & 0 & 0 & & \\
\hline$\%$ & 2,8 & 0 & 0 & & \\
\hline \multicolumn{6}{|l|}{ KB Alamiah } \\
\hline $\mathrm{f}$ & 38 & 2 & 1 & & \\
\hline$\%$ & 4,3 & 20 & 11,1 & & \\
\hline \multicolumn{6}{|l|}{ Total } \\
\hline $\mathrm{f}$ & 888 & 10 & 9 & & \\
\hline$\%$ & 100 & 100 & 100 & & \\
\hline
\end{tabular}

Sumber: Data Primer Tahun 2014

hubungan antara agama dengan keikutsertaan KB (agama melarang) sebagian besar memilih kontrasepsi suntik sejumlah 43 orang $(31,6 \%)$. Pasangan usia subur (PUS) yang memiliki keyakinan bahwa tidak ada hubungan antara agama dengan keikutsertaan KB (agama tidak melarang) sebagian besar memilih kontrasepsi suntik sejumlah 215 orang $(27,9 \%)$.

Hasil perhitungan statistik menggunakan uji chi-square seperti disajikan pada Tabel 9 diperoleh $p$-value sebesar $0,010<0,05$ sehingga dapat disimpulkan ada hubungan antara keyakinan dengan pemilihan jenis alat kontrasepsi. Nilai koefisien kontigensi 0,148 menunjukan hubungan antara keyakinan dengan pemilihan jenis alat kontrasepsi adalah sangat rendah.

Tabel 10 menunjukkan pasangan usia subur (PUS) yang memiliki keyakinan bahwa ada hubungan antara agama dengan keikutsertaan KB (agama melarang) sebagian besar memilih kontrasepsi hormonal (Pil, Suntik, Implant) sejumlah 60 orang $(44,1 \%)$. Pasangan usia subur (PUS) yang memiliki keyakinan bahwa tidak ada hubungan antara agama dengan keikutsertaan KB (agama tidak melarang) sebagian besar memilih kontrasepsi hormonal (Pil, Suntik, Implant) sejumlah 314 orang $(40,7 \%)$.
Tabel 9. Tabulasi Silang Hubungan Keyakinan dengan Pemilihan Jenis Alat Kontrasepsi di Desa Argomulyo, Sedayu, Bantul, Yogyakarta

\begin{tabular}{|c|c|c|c|c|c|}
\hline \multirow{2}{*}{$\begin{array}{c}\text { Pemilihan } \\
\text { Jenis KB }\end{array}$} & \multicolumn{2}{|c|}{ Keyakinan } & \multirow{2}{*}{$\chi_{\text {hitung }}^{2}$} & \multirow{2}{*}{ p-value } & \multirow{2}{*}{$\begin{array}{l}\text { Contigency } \\
\text { Coefficienct }\end{array}$} \\
\hline & Ya & Tidak & & & \\
\hline \multicolumn{6}{|c|}{ Tidak Memilih } \\
\hline$f$ & 39 & 28 & 20,026 & 0,010 & 0,148 \\
\hline$\%$ & 28,7 & 33,5 & & & \\
\hline \multicolumn{6}{|l|}{ PIL } \\
\hline$f$ & 12 & 80 & & & \\
\hline$\%$ & 8,8 & 10,4 & & & \\
\hline \multicolumn{6}{|l|}{ IUD } \\
\hline$f$ & 8 & 105 & & & \\
\hline$\%$ & 5,9 & 13,6 & & & \\
\hline \multicolumn{6}{|l|}{ Suntik } \\
\hline $\mathrm{f}$ & 43 & 215 & & & \\
\hline$\%$ & 31,6 & 27,9 & & & \\
\hline \multicolumn{6}{|l|}{ Implant } \\
\hline f & 5 & 19 & & & \\
\hline$\%$ & 3,7 & 2,5 & & & \\
\hline \multicolumn{6}{|l|}{ Kondom } \\
\hline$f$ & 9 & 48 & & & \\
\hline$\%$ & 6,6 & 6,2 & & & \\
\hline \multicolumn{6}{|l|}{ Sterilisasi } \\
\hline $\mathrm{f}$ & 7 & 18 & & & \\
\hline$\%$ & 5,1 & 2,3 & & & \\
\hline \multicolumn{6}{|c|}{ Pantang Berkala } \\
\hline f & 10 & 21 & & & \\
\hline$\%$ & 7,4 & 2,7 & & & \\
\hline \multicolumn{6}{|l|}{ Lain-Lain } \\
\hline f & 3 & 7 & & & \\
\hline$\%$ & 2,2 & 0,9 & & & \\
\hline \multicolumn{6}{|l|}{ Total } \\
\hline$f$ & 136 & 771 & & & \\
\hline$\%$ & 100 & 100 & & & \\
\hline
\end{tabular}

Sumber: Data Primer Tahun 2014

Hasil perhitungan statistik menggunakan uji chisquare seperti disajikan pada Tabel 10 diperoleh $p$-value sebesar 0,002<0,05 sehingga dapat disimpulkan ada hubungan antara keyakinan dengan pemilihan jenis alat kontrasepsi yang dikategorikan. Nilai koefisien kontigensi 0,143 menunjukan hubungan antara keyakinan dengan pemilihan jenis alat kontrasepsi yang dikategorikan adalah sangat rendah.

Responden menghindari kontrasepsi yang menurut keyakinan didalam ajaran agama mereka dilarang. Menurut Handayani beberapa tempat, kepercayaan religius dapat mempengaruhi masyarakat dalam memilih metode kontrasepsi(7). Menurut BKKBN, MUI menyampaikan pandangan islam terhadap metode kontrasepsi sebagai berikut: Suntik dan implant boleh digunakan dan tidak dilarang, IUD boleh digunakan dengan syarat dilakukan oleh dokter perempuan, sebagaimana tertuang dalam fatwa MUI 
Tabel 10. Tabulasi Silang Hubungan Keyakinan dengan Pemilihan Jenis Alat Kontrasepsi yang dikategorikan di Desa Argomulyo, Sedayu, Bantul, Yogyakarta Tahun 2014

\begin{tabular}{|c|c|c|c|c|c|}
\hline $\begin{array}{c}\text { Pemilihan } \\
\text { Jenis KB }\end{array}$ & \multicolumn{2}{|c|}{ Keyakinan } & $\chi_{\text {hitung }}^{2}$ & p-value & $\begin{array}{l}\text { Contigency } \\
\text { Coefficienct }\end{array}$ \\
\hline \multicolumn{6}{|c|}{ Tidak Memilih } \\
\hline $\mathrm{f}$ & 39 & 28 & 19,016 & 0,002 & 0,143 \\
\hline$\%$ & 28,7 & 33,5 & & & \\
\hline \multicolumn{6}{|c|}{ KB Hormonal } \\
\hline f & 60 & 314 & & & \\
\hline$\%$ & 44,1 & 40,7 & & & \\
\hline \multicolumn{6}{|l|}{ IUD } \\
\hline$f$ & 8 & 105 & & & \\
\hline$\%$ & 5,9 & 13,6 & & & \\
\hline \multicolumn{6}{|l|}{ Kondom } \\
\hline f & 9 & 48 & & & \\
\hline$\%$ & 6,6 & 6,2 & & & \\
\hline \multicolumn{6}{|l|}{ Sterilisasi } \\
\hline f & 7 & 18 & & & \\
\hline$\%$ & 5,1 & 2,3 & & & \\
\hline \multicolumn{6}{|c|}{ KB Alamiah } \\
\hline f & 13 & 28 & & & \\
\hline$\%$ & 9,6 & 3,6 & & & \\
\hline \multicolumn{6}{|l|}{ Total } \\
\hline $\mathrm{f}$ & 136 & 771 & & & \\
\hline$\%$ & 100 & 100 & & & \\
\hline
\end{tabular}

Sumber: Data Primer Tahun 2014

30 Oktober 1983, Pemutusan saluran (vasektomi dan tubektomi) dalam fatwa MUI 30 Oktober diharamkan, karena mempunyai sifat permanen sebagai illat atau sebabnya(2).

\section{KB yang Tidak Diijinkan Menurut Keyakinan PUS}

Tabel 11 menunjukkan bahwa sebagian besar KB yang tidak diijinkan menurut keyakinan memilih kontrasepsi sterilisasi sejumlah 145 orang (78,8\%). Sedangkan KB yang tidak diijinkan menurut keyakinan yang memilih kontrasepsi Pil paling sedikit yaitu 1 orang $(0,5 \%)$.

Sterilisasi merupakan pemutusan saluran (vasektomi dan tubektomi). Vasektomi adalah operasi kecil yang dilakukan untuk menghalangi keluarnya sperma dengan cara mengikat dan memotong saluran mani (Vas defferent) sehingga sperma tidak keluar pada saat senggama(8). Tubektomi/MOW (Medis Operatif Wanita): Tubektomi adalah prosedur bedah sukarela untuk menghentikan fertilitas (kesuburan) seorang perempuan(9).

Pasangan Usia Subur sebagian besar memilih kontrasepi sterilisasi untuk KB yang tidak diijinkan. $\mathrm{Hal}$ ini disebabkan sterilsasi merupakan KB yang diharamkan.
Tabel 11. KB yang Tidak Diijikan Menurut Keyakinan Pasangan Usia Subur di Desa Argomulyo, Sedayu, Bantul, Yogyakarta tahun 2014

\begin{tabular}{lcc}
\hline Jenis KB & $\mathbf{f}$ & $\mathbf{\%}$ \\
\hline IUD & 12 & 6,5 \\
Implant & 5 & 2,7 \\
Suntik & 4 & 2,2 \\
Pil & 1 & 0,5 \\
Sterilisasi & 145 & 78,8 \\
Pantang berkala & 15 & 8,2 \\
Kondom & 2 & 1,1 \\
Jumlah & 184 & 100 \\
\hline
\end{tabular}

Sumber: Data Primer Tahun 2014

\section{Hubungan antara Agama dengan KB yang Tidak Diijinkan Menurut Keyakinan}

Tabel 12 menunjukkan KB yang tidak diijinkan menurut keyakinan pasangan usia subur (PUS) dalam agama Islam sebagian besar memilih kontrasepsi sterilisasi sejumlah 143 orang $(78,6 \%)$. Sedangkan KB yang tidak diijinkan menurut keyakinan pasangan usia subur (PUS) dalam agama Kristen dan Khatolik

Tabel 12. Tabulasi Silang Hubungan Agama dengan KB Yang Tidak Diijinkan Menurut Keyakinan PUS di Desa Argomulyo, Sedayu, Bantul, Yogyakarta Tahun 2014

\begin{tabular}{|c|c|c|c|c|c|}
\hline \multirow{2}{*}{$\begin{array}{c}\text { KB yang } \\
\text { Tidak } \\
\text { Diijinkan }\end{array}$} & \multicolumn{3}{|c|}{ Keyakinan } & \multirow{2}{*}{$\chi_{\text {hitung }}^{2}$} & \multirow{2}{*}{ p-value } \\
\hline & Islam & Kristen & Katholik & & \\
\hline \multicolumn{6}{|l|}{ IUD } \\
\hline$f$ & 12 & 0 & 0 & 0,544 & 1,000 \\
\hline$\%$ & 6,6 & 0 & 0 & & \\
\hline \multicolumn{6}{|l|}{ Implant } \\
\hline f & 5 & 0 & 0 & & \\
\hline$\%$ & 5,7 & 0 & 0 & & \\
\hline \multicolumn{6}{|l|}{ Suntik } \\
\hline $\mathrm{f}$ & 4 & 0 & 0 & & \\
\hline$\%$ & 2,2 & 0 & 0 & & \\
\hline \multicolumn{6}{|l|}{ PIL } \\
\hline$f$ & 1 & 0 & 0 & & \\
\hline$\%$ & 0,5 & 0 & 0 & & \\
\hline \multicolumn{6}{|l|}{ Sterilisasi } \\
\hline f & 143 & 1 & 1 & & \\
\hline$\%$ & 78,6 & 100 & 100 & & \\
\hline \multicolumn{6}{|c|}{ Pantang Berkala } \\
\hline $\mathrm{f}$ & 15 & 0 & 0 & & \\
\hline$\%$ & 8,2 & 0 & 0 & & \\
\hline \multicolumn{6}{|l|}{ Kondom } \\
\hline$f$ & 2 & 0 & 0 & & \\
\hline$\%$ & 1,1 & 0 & 0 & & \\
\hline \multicolumn{6}{|l|}{ Total } \\
\hline$f$ & 182 & 1 & 1 & & \\
\hline$\%$ & 100 & 100 & 100 & & \\
\hline
\end{tabular}

Sumber: Data Primer Tahun 2014 
Tabel 13. Tabulasi silang hubungan Keikutsertaan KB dengan KB yang tidak diijinkan menurut keyakinan PUS di Desa Argomulyo, Sedayu, Bantul, Yogyakarta Tahun 2014

\begin{tabular}{|c|c|c|c|c|}
\hline \multirow{2}{*}{$\begin{array}{l}\text { KB yang Tidak } \\
\text { Diijinkan }\end{array}$} & \multicolumn{2}{|c|}{ Keikutsertaan KB } & \multirow{2}{*}{$\mathbf{X}_{\text {hitung }}^{2}$} & \multirow{2}{*}{$p$-value } \\
\hline & Ya & Tidak & & \\
\hline \multicolumn{5}{|l|}{ IUD } \\
\hline$f$ & 7 & 5 & 3,109 & 0,795 \\
\hline$\%$ & 5,5 & 8,9 & & \\
\hline \multicolumn{5}{|l|}{ Implant } \\
\hline f & 3 & 2 & & \\
\hline$\%$ & 2,3 & 3,6 & & \\
\hline \multicolumn{5}{|l|}{ Suntik } \\
\hline $\mathrm{f}$ & 2 & 2 & & \\
\hline$\%$ & 1,6 & 3,6 & & \\
\hline \multicolumn{5}{|l|}{ PIL } \\
\hline $\mathrm{f}$ & 1 & 0 & & \\
\hline$\%$ & 0,8 & 0 & & \\
\hline \multicolumn{5}{|l|}{ Sterilisasi } \\
\hline f & 102 & 43 & & \\
\hline$\%$ & 79,7 & 76,8 & & \\
\hline \multicolumn{5}{|l|}{ Pantang Berkala } \\
\hline $\mathrm{f}$ & 11 & 4 & & \\
\hline$\%$ & 8,6 & 7,1 & & \\
\hline \multicolumn{5}{|l|}{ Kondom } \\
\hline $\mathrm{f}$ & 2 & 0 & & \\
\hline$\%$ & 1,6 & 0 & & \\
\hline \multicolumn{5}{|l|}{ Total } \\
\hline$f$ & 128 & 56 & & \\
\hline$\%$ & 100 & 100 & & \\
\hline
\end{tabular}

Sumber: Data Primer Tahun 2014

sebagian besar memilih kontrasepsi sterilisasi sejumlah 1 orang (100\%).

Hasil perhitungan statistik menggunakan uji chi-square seperti disajikan pada Tabel 12 diperoleh $p$-value sebesar $1,000>0,05$ sehingga dapat disimpulkan tidak ada hubungan antara agama dengan KB yang tidak diijinkan menurut keyakinan PUS.

\section{Hubungan antara Keikutsertaan KB dengan KB yang tidak diijinkan menurut keyakinan PUS}

Tabel 13 menunjukkan KB yang tidak diijinkan menurut keyakinan pasangan usia subur (PUS) dan PUS ikut KB sebagian besar memilih kontrasepsi sterilisasi sejumlah 102 orang $(79,7 \%)$. Sedangkan KB yang tidak diijinkan menurut keyakinan pasangan usia subur (PUS) dan tidak ikut KB sebagian besar memilih kontrasepsi sterilisasi sejumlah 43 orang $(76,8 \%)$.

Hasil perhitungan statistik menggunakan uji chisquare seperti disajikan pada Tabel 13 diperoleh $p$-value sebesar 0,795>0,05 sehingga dapat disimpulkan tidak ada hubungan antara keikutsertaan KB dengan KB yang tidak diijinkan menurut keyakinan PUS.

\section{SIMPULAN DAN SARAN}

Berdasarkan hasil analisis yang telah dilakukan dapat ditarik kesimpulan karakteristik pasangan usia subur di Desa Argomulyo, Sedayu, Bantul, Yogyakarta: Sebagian besar istri 20-35 tahun sejumlah 476 orang $(52,5 \%)$ dan Suami berusia $>35$ tahun sejumlah 523 orang $(57,7 \%)$. Sebagian besar Istri berpendidikan SMA sejumlah 548 orang $(60,4 \%)$ dan pendidikan suami sebagian besar SMA sejumlah 563 orang $(62,1 \%)$, sebagian besar memiliki anak $<2$ orang sejumlah 705 (78,9\%). Sebagian besar Pasangan Usia Subur (PUS) beragama Islam sejumlah 888 orang $(97,9 \%)$. Responden yang memiliki keyakinan dalam ajaran agama dengan keikutsertaan KB (agama melarang) sejumlah 136 orang $(15,0 \%)$ dan memiliki tidak meyakini dalam ajaran agama dengan keikutsertaan KB (agama tidak melarang) sejumlah 771 orang $(85,0 \%)$. Pasangan Usia Subur (PUS) yang ikut KB sejumlah 610 orang $(67,3 \%)$ dan responden yang tidak ikut KB sejumlah 297 orang $(32,7 \%)$. Responden sebagian besar memilih kontrasepsi Suntik sejumlah 258 orang (42,3\%), sedangkan yang memilih kontrasepsi Metode Amenore Laktasi (MAL) dan senggama terputus jumlahnya paling sedikit sejumlah 10 orang $(1,6 \%)$. Tidak ada hubungan yang bermakna antara Agama pasangan usia subur (PUS) dengan Keikutsertaan KB. Tidak ada hubungan yang bermakna antara Keyakinan pasangan usia subur (PUS) dengan Keikutsertaan KB. Tidak ada hubungan yang bermakna antara Agama pasangan usia subur (PUS) dengan Pemilihan Jenis Alat Kontrasepsi. Ada hubungan yang bermakna antara Keyakinan Pasangan Usia Subur dengan Pemilihan Jenis Alat Kontrasepsi. Saran bagi PUS agar lebih meningkatkan pemahaman tentang alat kontrasepsi.

\section{RUJUKAN}

1. Sulistyawati A. Pelayanan Keluarga Berencana. Yogyakarta: Salemba Medika; 2013.

2. BKKBN. Kumpulan Materi KIE Forum Antar Umat Beragama Peduli Keluarga Sejahtera dan Kependudukan (FAPSEDU). Yogyakarta; 2012.

3. Hamid S. Faktor-faktor yang Berhubungan dengan Unmeet Need Keluarga Berencana. Universitas Indonesia; 2002.

4. Riyanto. Aplikasi Metodelogi Penelitian Kesehatan. Yogyakarta: Nuha Medika; 2011.

5. Aziz AH. Metode Penelitian Kebidanan dan Teknik Analisa Data. Jakarta: Salemba Medika; 2010.

6. Loemintoe L. Faktor-Faktor yang berhubungan dengan pemilihan jenis alat kontrasepsi pada akseptor KB di Puskesmas Pakualaman Yogyakarta. STIKES Alma Ata Yogyakarta; 2011. 
7. Handayani S. Buku Ajar Pelayanan Keluarga Berencana. Yogyakarta: Pustaka Rihama; 2010.

8. Suratun, Srimaryani, Tien H, Rusmiati, Saroha P. Pelayanan Keluarga Berencana dan Pelayanan Kontrasepsi. Jakarta: Trans Info Media; 2008.

9. Arum, Dyah NS, Sujiyati. Panduan Lengkap Pelayanan KB Terkini. Yogyakarta: Nuha Medika; 2009. 